\title{
Study on Performance of Steel Fiber Concrete Bridge Pier Specimens under Horizontal Cyclic Loading
}

\author{
Chen Baiben ${ }^{1, a}$, Feng Zhongren ${ }^{1}$ and Shi Xiaoji ${ }^{1}$ \\ ${ }^{1}$ School of Civil Engineering and Architecture, Wuhan University of Technology, 430070 Wuhan Hubei, China
}

\begin{abstract}
Because of that steel fiber can effectively prevent the extension and development of small cracks in the concrete, steel fiber reinforced concrete has good toughness and tensile strength. In the application of building materials, steel fiber reinforced concrete is an ideal elastic-plastic material. For the seismic performance, it has advantages. In order to analyze the seismic performance of steel fiber reinforced concrete, 4 piers of the scale model test under horizontal cyclic loading were done. The results showed that failure mode of steel fiber reinforced concrete is better than that of ordinary concrete, and has a large yield moment under the external loads.
\end{abstract}

\section{Introduction}

The steel fiber concrete is different from ordinary concrete, which adds steel fibers into concrete, in which cement and steel fibers shared external force in the early loaded. The cement is the main bearing material for external load. With the increasing of load, the cracks in concrete became increasing and have the development trends in the whole material. In this time, the steel fibers have tension and are continuing into the loading stage, them bear lots of load force. Different from that ordinary concrete cracking is the failure of cement, steel fiber reinforced concrete is mainly due to steel fiber pull-out from the concrete, resulting in the entire concrete cracking, loss of tensile properties.

Due to incorporation of steel fiber, the fiber material and cement in the concrete combine into one in the steel fiber reinforced concrete, the levels of strength, toughness and tensile properties are increasing. It has lots of advantages over traditional materials in building materials. Especially in recent years, the extensive development of bridge construction is vary fast, the steel fiber reinforced concrete can effectively prevent the coupling effect of the pier in horizontal and vertical seismic force, deformation, shear force and cracking can be control, and the structure will not damage in earthquake.

21 steel fiber reinforced high-strength concrete columns were done the eccentric and non eccentric loading test by Foster [1], and the bearing capacity and ductility of steel fiber on concrete columns would be improved. 26 steel fiber reinforced high-strength concrete column bending performance test under low cyclic loading were done by $\mathrm{Li}$ Fenglan [2], the axial compression ratio, characteristics value of steel fiber content, stirrup characteristic value, shear span ratio and longitudinal reinforcement and other factors on the influence of the ductility of steel fiber reinforced high strength concrete performance were researched. Zhu Zhao [3] used finite element software to establish the local steel fiber reinforced concrete bridge pier model, and analyzed the reasonable distribution of pier steel fiber length. Zhang Yuye [4-6] through the experiment of steel fiber reinforced concrete pier, proposed a reasonable length of steel fiber reinforced concrete using local formula. The scholars [7-9] at home and abroad have also studied the mechanical properties of steel fiber reinforced concrete and its application in frame columns, the shear resistance and the structural energy dissipation of the steel fiber reinforced concrete are obviously improved.

The horizontal cyclic loading performance tests of four steel fiber reinforced concrete bridge pier specimens were analyzed. In different steel fiber volume, seismic performances of bridge material were compared, which reflect the yield failure patterns of steel fiber reinforced concrete in cyclic load under the condition of the horizontal cyclic loading.

\section{Constitutive relation of concrete under cyclic loading}

It is well known that the unloading paths and loading paths of concrete are quite different except at low stress levels. When unloading to the initial stress state, the strain does not recover completely, but retains a part of the permanent strain (plastic strain). In some applications, in order to simulate the properties under cyclic loading conditions, the simple model is combined with the loading criterion. The loading criterion is not related to the constitutive relation. For unloading scenarios, it is assumed that the deformation is due to the control of the

\footnotetext{
a Corresponding author: cbb0505@163.com
} 
modulus of elasticity different from the loading conditions. But there are problems such as uniqueness and continuity.

For concrete materials, it is difficult to simulate the cyclic loading capacity and simulate the degradation of strength and stiffness of concrete. Normally, need a similar strain introduced to simulate the deformation history and determine the amount of a single hysteresis behavior. The concept of equivalent uniaxial strain can be used to solve such problems.

By using the incremental constitutive equation and the shear stiffness assumption expressed by other material constants, the incremental constitutive relation expressed in terms of incremental uniaxial strain is given. On this basis, the relationship between equivalent uniaxial strain and stress is introduced to form the basis of incremental elastic modulus derived from stress and equivalent uniaxial strain parameters.

\subsection{Incremental constitutive relation}

Under biaxial stress conditions, the orthotropic increment stress-strain relation can be written:

$$
\left\{\begin{array}{l}
\dot{\sigma}_{11} \\
\dot{\sigma}_{22} \\
\dot{\tau}_{12}
\end{array}\right\}=\frac{1}{1-v_{1} v_{2}}\left[\begin{array}{ccc}
E_{1} & v_{2} E_{2} & 0 \\
v_{1} E_{2} & E_{2} & 0 \\
0 & 0 & \left(1-v_{1} v_{2}\right) G
\end{array}\right]\left\{\begin{array}{l}
\dot{\varepsilon}_{11} \\
\dot{\varepsilon}_{22} \\
\dot{\gamma}_{12}
\end{array}\right\}
$$

Among them, $E_{1}, v_{1}$ and $E_{2}, v_{2}$ are tangent elastic moduli along the orthotropic principal axes 1 and 2 , and $G$ is the tangent shear modulus related to the axes 1 and 2 .

The equivalent Poisson's ratio $\mu$ is defined as follows:

$$
\mu^{2}=v_{1} v_{2}
$$

Suppose that the shear modulus $G$ is the invariant of the shaft transformation:

$$
\left(1-\mu^{2}\right) G=\frac{1}{4}\left(E_{1}+E_{2}-2 \mu \sqrt{E_{1} E_{2}}\right)
$$

Therefore, the formula (1) can be turned into:

$$
\left\{\begin{array}{l}
d \sigma_{1} \\
d \sigma_{2} \\
d \tau_{12}
\end{array}\right\}=\frac{1}{\left(1-\mu^{2}\right)}\left[\begin{array}{ccc}
E_{1} & \mu \sqrt{E_{1} E_{2}} & 0 \\
0 & E_{2} & 0 \\
0 & \mu \sqrt{E_{1} E_{2}} & \frac{1}{4}\left(E_{1}+E_{2}-2 \mu \sqrt{E_{1} E_{2}}\right)
\end{array}\right]\left\{\begin{array}{l}
d \varepsilon_{1} \\
d \varepsilon_{2} \\
d \gamma_{12}
\end{array}\right\}
$$

\subsection{Equivalent uniaxial strain}

The variation of the tangent modulus $E_{1}$ and $E_{2}$ with the stress is determined by introducing the concept of equivalent uniaxial strain, assuming that the formula (4) is as follows:

$$
\left\{\begin{array}{l}
d \sigma_{1} \\
d \sigma_{2} \\
d \tau_{12}
\end{array}\right\}=\left[\begin{array}{ccc}
E_{1} B_{11} & E_{1} B_{12} & 0 \\
E_{2} B_{21} & E_{2} B_{22} & 0 \\
0 & 0 & G
\end{array}\right]\left\{\begin{array}{l}
d \varepsilon_{1} \\
d \varepsilon_{2} \\
d \gamma_{12}
\end{array}\right\}
$$

Among them, the coefficient $B_{i j}(i, j=1,2)$ can be determined by making the matrix entries in formula (5) correspond to the corresponding items in formula (4). By calculation:

$$
\begin{aligned}
& d \sigma_{1}=E_{1}\left(B_{11} d \varepsilon_{1}+B_{12} d \varepsilon_{2}\right) \\
& d \sigma_{2}=E_{2}\left(B_{21} d \varepsilon_{1}+B_{22} d \varepsilon_{2}\right) \\
& d \tau_{12}=G d \gamma_{12}
\end{aligned}
$$

The upper form can be written as follows:

$$
\left\{\begin{array}{l}
d \sigma_{1} \\
d \sigma_{2} \\
d \tau_{12}
\end{array}\right\}=\left[\begin{array}{ccc}
E_{1} & 0 & 0 \\
0 & E_{2} & 0 \\
0 & 0 & G
\end{array}\right]\left\{\begin{array}{l}
d \varepsilon_{1 u} \\
d \varepsilon_{2 u} \\
d \gamma_{12}
\end{array}\right\}
$$

The strain vector of each formula zip code is defined as the equivalent increment single axis strain vector, and the definition of its element is accomplished by the corresponding increment of the actual strain increment and the formula (6):

$$
d \varepsilon_{1 u}=B_{i 1} d \varepsilon_{1}+B_{i 2} d \varepsilon_{2}
$$

The total equivalent effect can be obtained by integrating the equivalent uniaxial strain:

$$
\varepsilon_{i u}=\int \frac{d \sigma_{i}}{E_{i}}
$$

\section{Steel fiber reinforced concrete column specimens}

The test specimens were made of $\mathrm{C} 40$ concrete, which is made of steel fiber with a certain volume proportion in commercial concrete. Among them, every cubic meters of concrete materials: water is $160 \mathrm{~kg}$; cement is $240 \mathrm{~kg}$; sand is $782 \mathrm{~kg}$; stone is $1038 \mathrm{~kg}$; admixture is $180 \mathrm{~kg}$ and additive is $6.0 \mathrm{~kg}$. Mass ratio is like that, water: cement: sand: stone: admixture: additive $=0.67: 1: 3.26: 4.58: 0.25$ : 0.50 . The ordinary concrete cube compressive strength for 28 days is $50.6 \mathrm{MPa}$, and that of steel fiber reinforced concrete is $51.7 \mathrm{MPa}$ in which steel fiber volume ratio is $1.5 \%$.

HRB500 high strength rebar is used for longitudinal bars which diameter is $20 \mathrm{~mm}$, and HRB335 steel is used for stirrup which diameter is $8 \mathrm{~mm}$.

Specimens are a total of four groups, ordinary concrete specimens is specimen $\mathrm{S}$, and the steel fiber volume ratio is different for steel fiber reinforced concrete specimens, which $1 \%$ is specimen $\mathrm{A}, 1.5 \%$ is specimen B, $2 \%$ is specimen C. Steel fiber is a kind of corrugated steel fiber, as shown in Figure 1. The test component parameter list are shown in Table 1. 


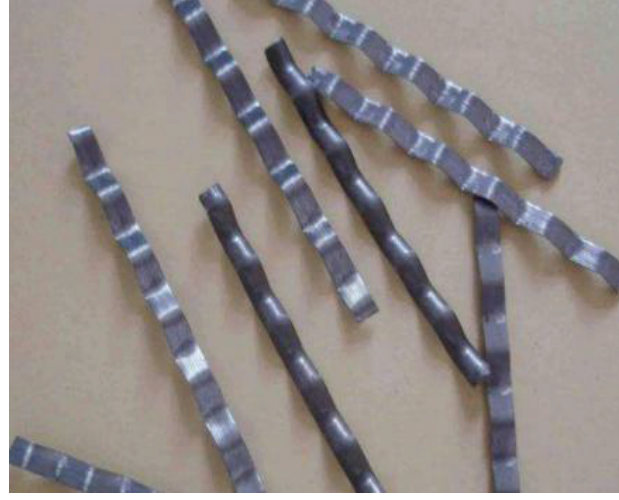

Figure 1. Corrugated steel fiber.

Table 1. Test component parameter list.

\begin{tabular}{|c|c|c|c|c|}
\hline No. & S & A & B & C \\
\hline Concrete & ordinary & $\begin{array}{c}\text { steel } \\
\text { fiber }\end{array}$ & $\begin{array}{c}\text { steel } \\
\text { fiber }\end{array}$ & $\begin{array}{c}\text { steel } \\
\text { fiber }\end{array}$ \\
\hline Main bar & HRB500 & HRB500 & HRB500 & HRB500 \\
\hline $\begin{array}{c}\text { Steel fiber } \\
\text { volume ratio } \\
\text { (\%) }\end{array}$ & $/$ & 1.0 & 1.5 & 2.0 \\
\hline Height (mm) & 1000 & 1000 & 1000 & 1000 \\
\hline $\begin{array}{c}\text { Longitudinal } \\
\text { reinforcement } \\
\text { diameter (mm) }\end{array}$ & 20 & 20 & 20 & 20 \\
\hline $\begin{array}{c}\text { Longitudinal } \\
\text { reinforcement } \\
\text { ratio (\%) }\end{array}$ & 3.14 & 3.14 & 3.14 & 3.14 \\
\hline $\begin{array}{c}\text { Stirrup } \\
\text { diameter (mm) }\end{array}$ & 8 & 8 & 8 & 8 \\
\hline $\begin{array}{c}\text { Spacing } \\
\text { between } \\
\text { stirrups (mm) }\end{array}$ & 80 & 80 & 80 & 80 \\
\hline $\begin{array}{c}\text { Volume stirrup } \\
\text { ratio (\%) }\end{array}$ & 1.14 & 1.14 & 1.14 & 1.14 \\
\hline $\begin{array}{c}\text { Axial } \\
\text { compression } \\
\text { ratio }\end{array}$ & 0.1 & 0.1 & 0.1 & 0.1 \\
\hline
\end{tabular}

The specimens were made of solid square section, the size of the pier column is $300 \mathrm{~mm} \times 300 \mathrm{~mm}$, the height is $1000 \mathrm{~mm}$, and the bottom was set with a fixed cap. The section size and reinforcement of the pier column model are shown in Figure 2. The forming specimen is shown in Figure 3.

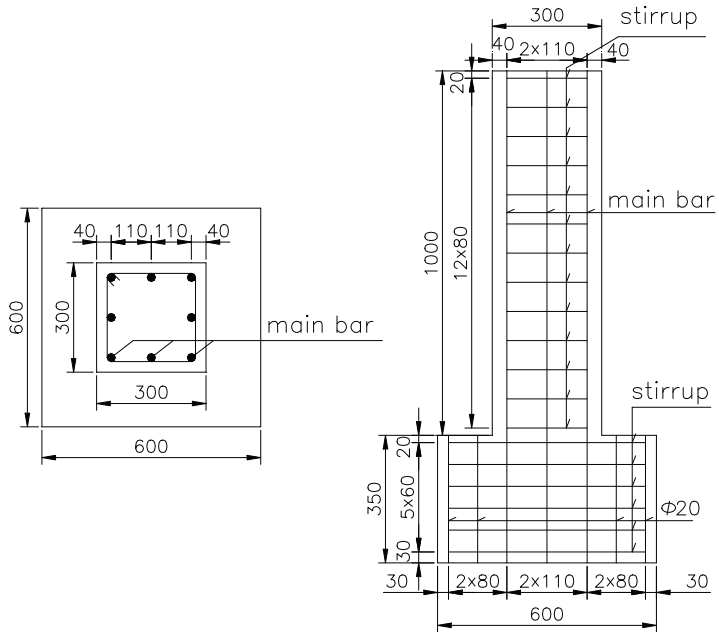

Figure 2. Section size and reinforcement (unit: $\mathrm{mm}$ ).

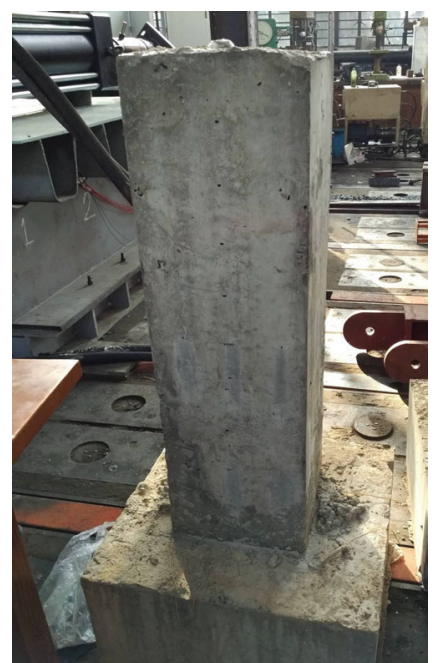

Figure 3. The forming specimen for test

\section{Horizontal cyclic loading test}

The test load is carried out by 10t-100t hydraulic servo static and dynamic loading system, the maximum horizontal load is $1000 \mathrm{kN}$, the maximum horizontal displacement is $1000 \mathrm{~mm}$. The vertical force is realized by adding hydraulic jack on the top of the specimen. The horizontal load is controlled by displacement amplitude and the displacement is $3,6,9,12,15,18,21,24,27,30$, $35,40,45,50,55$ and $60 \mathrm{~mm}$. At the bottom of the specimen, by using hoop frame to fix in the geosynclines. The loading device is shown in Figure 4.

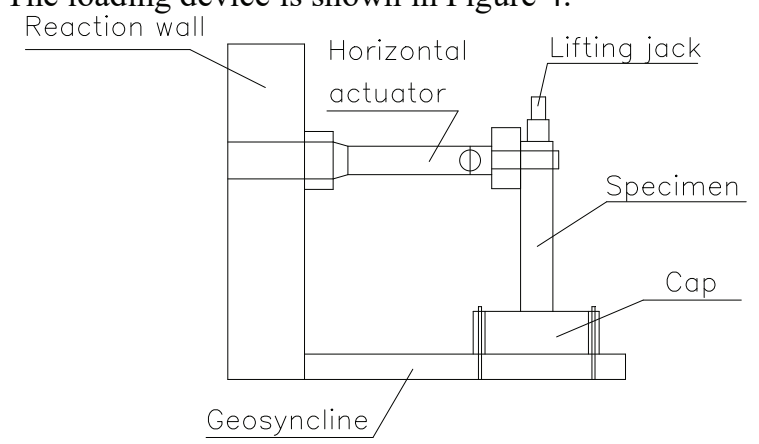

Figure 4. Horizontal cyclic loading test device. 


\section{Failure patterns}

\subsection{Failure characteristics of ordinary concrete (specimens S)}

Under cyclic loading, the crack of the specimen increases gradually with the increase of displacement. The first crack appears at the time of displacement is $9 \mathrm{~mm}$, the position of first crack from the $311 \mathrm{~mm}$ along the height direction of the specimen extends along the 45 degree angle into the middle lower place. With the increase of displacement, the cracks increase gradually, and the crack width increases. When the displacement is $24 \mathrm{~mm}$, through cracks from left to right is formed, and the width is about $3 \mathrm{~mm}$. when the displacement reaches $30 \mathrm{~mm}$, the surrounding concrete scaling appear because of concrete crushing, confined concrete by stirrup continue to bear force based on confined effect from hoop steels. When the displacement is $45 \mathrm{~mm}$, the steel reinforcement of the specimen yield, and the concrete in the cross section falls off, and the load can not be improved. The specimen failure is shown in Figure 5.

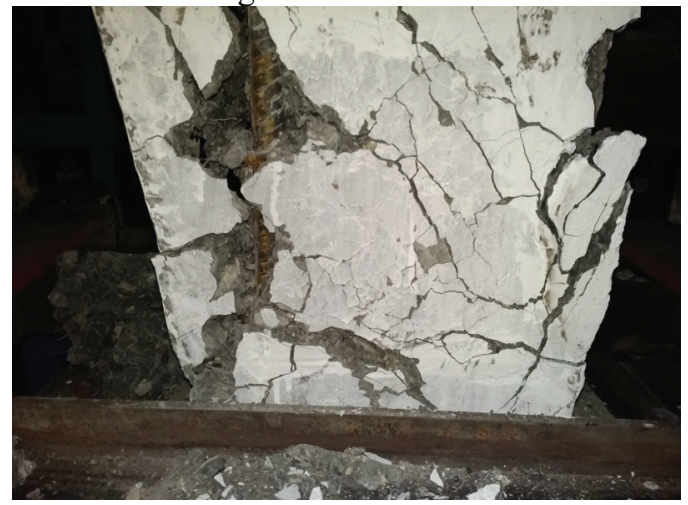

Figure 5. Failure characteristics of ordinary concrete specimens.

\subsection{Failure characteristics of steel fiber reinforced concrete (specimen B)}

Under cyclic loading, when the first crack appears to be $15 \mathrm{~mm}$, the crack is small and the development is slow. With the increase of displacement, the crack extends along the 45 degree angle, and the small transverse cracks occur near the main crack. When the displacement reaches $27 \mathrm{~mm}$, there is a relative penetration crack, the crack width is $1 \mathrm{~mm}$, the main crack width is larger, $2 \mathrm{~mm}$. Small cracks occur in the middle of the pier. When the displacement reaches $50 \mathrm{~mm}$, the left and right main cracks intersect with each other. When the displacement reaches the maximum value of the test, there is no large area shedding phenomenon in the concrete of the protective layer. The specimen failure is shown in Figure 6 . The failure characteristics of specimens $\mathrm{A}$ and $\mathrm{C}$ are similar to those of $\mathrm{B}$.

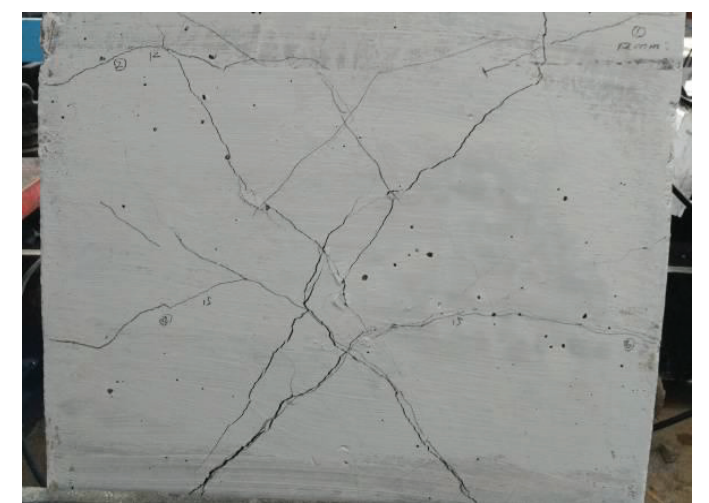

Figure 6. Failure characteristics of steel fiber reinforced concrete specimens.

According to the above characteristics, it can be seen that due to the effect of steel fiber, the internal crack of concrete is slow, the crack width is small, the number of small cracks increases, and the integrity of the components is better compared with ordinary concrete.

\section{Hysteretic curve}

According to the data of displacement by testing equipment at the top of pier, subtract to horizontal displacement at the bottom of pier, the horizontal load and lateral displacement of pier hysteretic curve of 4 specimens of pier were drawing combined with horizontal seat actuator afterburner. Figure 7 show the hysteretic curve of the specimens.

From the hysteretic curves, all the hysteretic curves have shape of "pinch" bow, the ordinary concrete specimen pinch form is small, on the same level of displacement under the action, it has the tendency to spread. The steel fiber concrete is not diffusion state role in repeated displacement under load, comparison of both lag the curve, steel fiber reinforced concrete specimens are plump, and the ordinary concrete specimen is low.

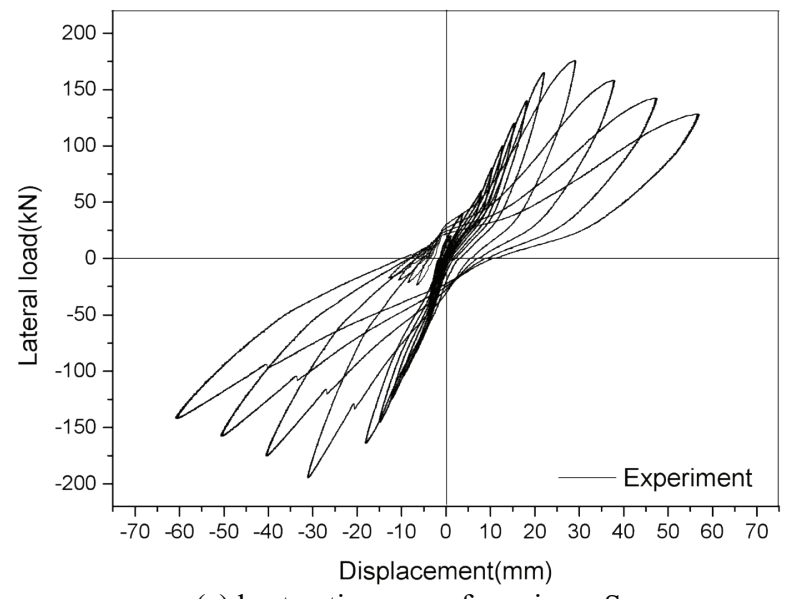

(a) hysteretic curve of specimen $\mathrm{S}$ 


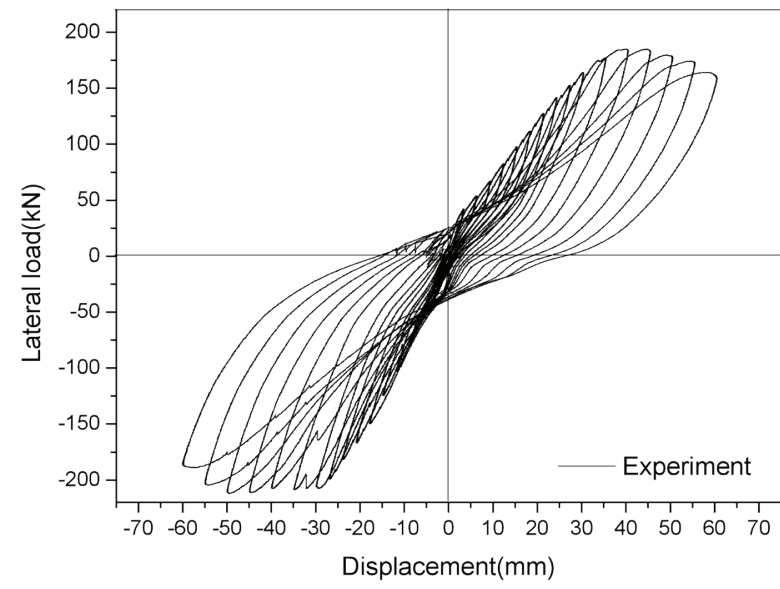

(b) hysteretic curve of specimen A

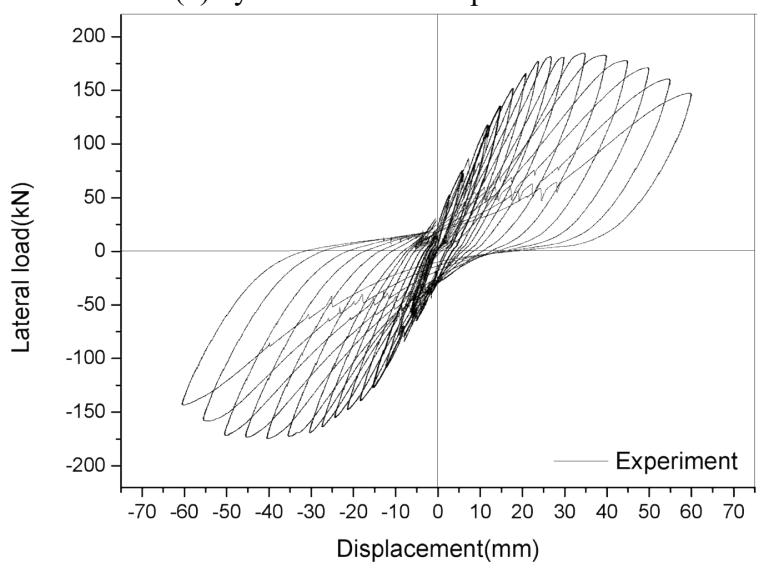

(c) hysteretic curve of specimen B

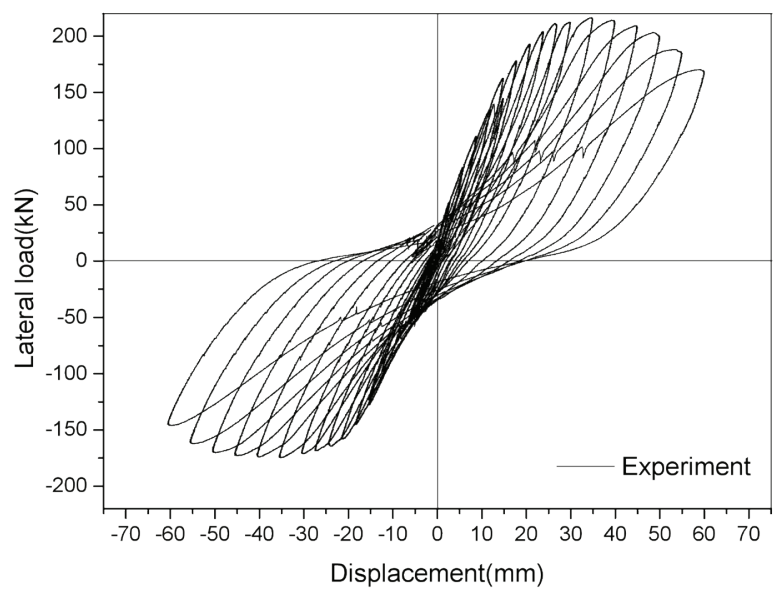

(d) hysteretic curve of specimen C

Figure 7. Hysteretic curves.

In the early stage of displacement loading, ordinary concrete specimen has the same change trend compared with steel fiber reinforced concrete specimens, with the increase of the displacement, the steel fiber concrete of change trend decreased more gently, and ordinary concrete is lower than that, which has larger slope. Comparison of both loading and unloading trend, ordinary concrete has asymmetrical shape, unloading slope is less than loading slope, but the loading and unloading slope of steel fiber concrete is consistent.

Comparing the three hysteretic curves of specimens which have different steel fiber content, the three forms are consistent, and show the ideal loading characteristics of elastic-plastic materials. The greater the amount of steel fiber mixing, the greater horizontal force under same displacement. It has a larger area surrounded by displacement force curve, which shows that the structure energy performance is good.

\section{Summary}

By comparing the test results of ordinary concrete and steel fiber reinforced concrete specimens with different steel fiber content, the following conclusions can be obtained by the combination of the failure mode and relevant data:

(1) Steel fiber concrete can prevent the development and extension of concrete cracks under the action of external force with the effect of steel fiber. Steel fiber reinforced concrete specimens in comparison with ordinary concrete, the crack of former appear earlier and the width is larger, the failure trend is obvious, and holding point is smaller; the latter under horizontal cyclic loading showed good integrity, the crack width is small and extends slowly, but small cracks are more.

(2) Compared with ordinary concrete specimens, the hysteretic curves of steel fiber reinforced concrete specimens are relatively full, and the displacement force curve has a large area, which has a better energy dissipation effect.

(3) The loading and unloading slope of steel fiber reinforced concrete specimens are more uniform, and the slope of the ordinary concrete specimen is small. The former has obvious elastic-plastic characteristics.

\section{Acknowledgments}

Thanks are given for financial support from the National Natural Science Foundation of China (NSFC), grant 51408449 .

\section{References}

1. S.J. Foster, M.M. Attard. Journal of Structural Engineering, 127, 28-34 (2001)

2. F.L. Li, C.K. Huang, S.C. Wen, etc. ENGINEERING MECHANICS, 22, 159-164 (2005) (in Chinese)

3. Z. Zhu, Y. Fu, P. Guo, etc. STRUCTURAL ENGINEERS, 20, 73-78 (2010) (in Chinese)

4. Y.Y. Zhang, K.A. Harries, W.C. Yuan. Engineering Structures, 48, 255-265 (2013)

5. Y.Y. Zhang, H.Y. Wei, W.C. Yuan. Journal of Vibration and Shock, 31, 102-107 (2012) (in Chinese)

6. Y.Y. Zhang, H.Y. Wei, W.C. Yuan. Journal of Tongji University(Natural Science), 41, 813-820 (2013) (in Chinese)

7. A. Demeke, I.A. Tegos. ACI Materials Journal, 91, 579-584 (1994)

8. R.S. Olivoto, F.A. Zuccarello. Composites Part B: Engineering, 41, 246-255 (2010)

9. P. Robins, S. Austin, J. Chandler, etc. Cement Concrete Research, 31, 719-729 (2001) 